\title{
Production and mechanical characterization of polyethylene matrix composites with the addition of linen and cotton waste fabric filler materials
}

\author{
Mehmet İpekoğlu ${ }^{1 *}$, Hasan Gündüz², Önder Albayrak ${ }^{3}$
}

'Turkish-German University, Faculty of Engineering, Department of Mechanical Engineering, 34820 Beykoz, Istanbul Turkey, ${ }^{2}$ Mersin University, Institute of Science, Department of Mechanical Engineering, 33343 Yenisehir, Mersin Turkey, ${ }^{3}$ Mersin University, Faculty of Engineering, Department of Mechanical Engineering, 33343 Yenisehir, Mersin Turkey

Orcid: M. İpekoğlu (0000-0002-00 I9-3346), H. Gündüz (0000-0002-6582-3564), Ö. Albayrak (0000-000I-59I8-3858)

Abstract: In this study, linen and cotton fibers obtained from fabric waste were used as filler materials and polyethylene was used as matrix material to produce fiber reinforced polymer composites using injection molding. Use of fabric waste as filler material enables utilization of linen and cotton wastes while decreasing amount of polyethylene used in the composites resulting in an environmentally friendly material. Prepared samples with varying content of linen and cotton wastes (5, 10 and 20 vol. \%) were compared with each other and with polyethylene samples without any filler, based on their yield, tensile and fracture strengths, percent elongation and hardness values. Samples were also evaluated for their chip formation characteristics based on chip lengths at various machining speeds and examined for their visual appearance. Results indicated that linen waste fibers can be used to improve strength of polyethylene based composites while cotton waste fibers can be utilized to enhance elongation characteristics of the samples.

Keywords: Fabric waste, linen, cotton, polyethylene, composite

\section{Introduction}

Textile consumption rapidly increases due to the increasing world population. Hence, fiber production is estimated to reach almost 130 million tons in 2025 with an annual growth rate of $3.7 \%$. Nearly $30 \%$ of this fiber production is estimated to be of cotton origin [1]. Literature reports that only 7.5 million tons of textile products can be recycled every year [2]. Therefore, any significant attempt to recycle the textile waste is of utmost importance not only due to its environmental impact but also for its financial aspects due to the economic use of resources.

Composite materials consist of a matrix material and filler materials combining the positive aspects of all materials used in combination [3]. Among composite materials, fiber reinforced polymer composites play a significant role in numerous industrial applications due their enhanced mechanical properties coupled with relatively low production costs. In order to improve the properties of polymer based composites various filler materials such as carbon fibers [4], glass fibers [5] and carbon nanotubes [6] have been studied as reinforcements and mechanical properties, surface roughness and machining parameters such as cutting speed and feed rate have been investigated
$[7,8]$.

Use of filler materials of natural origin has been studied in the production of polymer based composites. This enables production of composites with enhanced mechanical properties while taking their environmental impact into account and creating alternative materials with enhanced properties. Researchers used polyethylene as matrix and packaging paper as filler material and found out that tensile strength of the produced composites increase with increasing length of reinforcement fibers [9]. Another study reports use of hemp fibers to reinforce polypropylene matrix [10]. A further study about polypropylene matrix composites utilizing wood and cotton fibers as reinforcement materials points out that the amount of cotton fiber content at $10 \%$ decreased the tensile strength of the samples while increasing the amount of cotton fibers to 20 and $30 \%$ subsequently increased the tensile strength of the samples [11]. Another study evaluating the effect of the length of the wood fibers used as reinforcement in high density polyethylene reports that fiber length had a positive effect on the mechanical properties of the produced composites [12]. Increasing the cotton fiber composition enhanced the mechanical properties of 
polyethylene based composites [13] whereas an increase in the cotton fiber composition had in general a detrimental effect on tensile strength of polypropylene and polyvinyl chloride based composites [14]. This suggests that effect of cotton fiber addition strongly depends on the type of the matrix polymer used for the production of the composite materials. In a research conducted about the mechanical characterization of natural fiber reinforced epoxy composites it was found that the results were strongly affected by the type of treatment of fibers prior to addition into matrix material [15].

Further use of waste materials of natural origin as filler materials results in decreasing the rate of consumption of natural resources and decreasing the production costs [16]. Researchers incorporating wood chips as reinforcement in polyethylene matrix material found out that fracture elongation of the composites increased with accompanying enhancement of impact properties of the material. They concluded that wood chips of small dimensions limit the crack propagation in produced composites [17]. Another study suggests successful use of waste carpets to enhance strength and elongation of low density polyethylene [18].

Some studies specifically concentrate on the utilization of waste fabrics as filler materials in polymer based composites $[16,19,20]$. Waste cotton fabrics were used to increase the impact resistance of polyester matrix [16] whereas they positively affected tensile strength of low density polyethylene matrix [19]. Other researchers concluded that ramie addition positively affected the mechanical properties of polyester matrix composites whereas effect of cotton fibers remained limited [20]. The results found in literature clearly show that the mechanical properties are a result of the combination of the type, content and state of prior chemical treatment of the reinforcement fibers and the type of the polymer matrix used to produce the composites $[15,21]$.

Textile waste fibers of cotton and linen origin were used as filler materials throughout this study in order to produce polyethylene based polymer matrix composites. The produced cotton and linen waste fiber reinforced polyethylene composites were mechanically tested for their yield, ultimate tensile and fracture strengths, and their corresponding elongations. Hardness values and surface roughness of the composites were determined and compared based on the filler material type and concentration. Produced samples were optically characterized using microscopy imaging.

The aim of the current study is manufacturing of polyethylene matrix composites with the addition of linen and cotton waste fabric filler materials. Using linen and cotton wastes enables recycling of waste fibers and decreasing the amount of polyethylene used in the produced composites. The obtained final product is an environmentally friendly composite material with enhanced mechanical properties.

\section{Materials and Methods}

\section{I. Materials}

In order to determine the effect of filler type and content on mechanical properties of the obtained polyethylene matrix composites samples containing linen and cotton waste fibers with varying filler content $(5,10$ and 20 vol. $\%)$ were prepared along with a control sample containing no filler. Waste fabrics were manually cut into smaller strips (Figure 1.a) before the chopping process to prevent stalling of the chopper by wrapping of the fabric parts around the chopper blades. Shreds coming out of the chopper (Figure 1.b) were used as filler material in the polyethylene matrix composites.

Chopped filler materials of linen and cotton waste origin were mixed with polyethylene pellets (Figure 1.c) in varying ratios before being injection molded (DEMAG 60/150, Germany) (Figure 1.d-e) to prepare the samples according to ISO 527 [22] (Figure1.f). Designation of the samples based on filler type and content is given in Table 1.

\subsection{Methods}

Tensile testing was conducted to determine the effect of filler type and content on mechanical properties of the obtained composite specimens. Seven specimens in each sample set were tested for their yield, tensile and fracture strengths and \% elongation values. Tests were conducted at $5 \mathrm{~mm} / \mathrm{min}$ crosshead speed in a universal tensile test machine (Shimadzu AGX $50 \mathrm{kN}$ ).

\begin{tabular}{|c|c|c|}
\hline Sample & Linen (vol. \%) & Cotton (vol. \%) \\
\hline PE & - & - \\
\hline $5 \mathrm{~L} / \mathrm{PE}$ & 5 & - \\
\hline IOL/PE & 10 & - \\
\hline 20L/PE & 20 & - \\
\hline $5 \mathrm{C} / \mathrm{PE}$ & - & 5 \\
\hline I0C/PE & - & 10 \\
\hline 20C/PE & - & 20 \\
\hline
\end{tabular}

Hardness values of the specimen were measured using a durometer (Affri Shore D 3002, Italy) under ambient conditions and $55 \%$ humidity. Seven hardness measurements have been conducted for each sample on the midline of the prepared tensile test specimen starting with the middle point of the midline and 3 measurements have been conducted on both sides of the midpoint with a distance of $5 \mathrm{~mm}$ from each other.

In order to evaluate the effects of filler type, filler amount and milling speed on the chip formation characteristics 


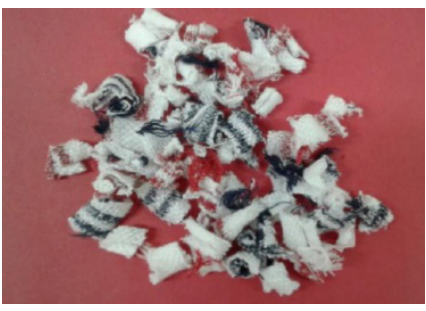

a)

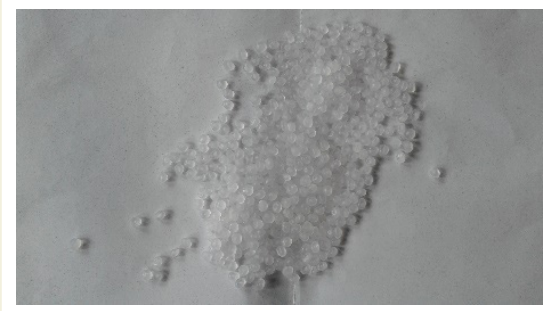

c)

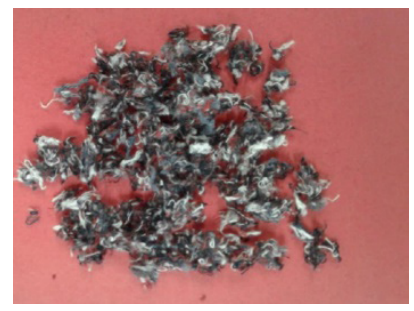

b)

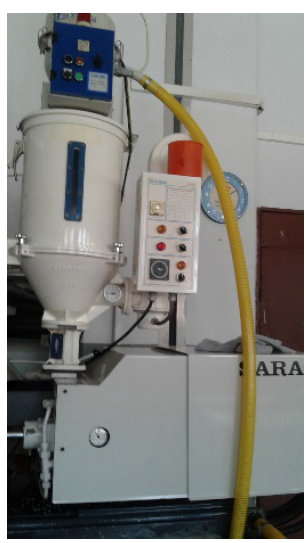

d)

e)

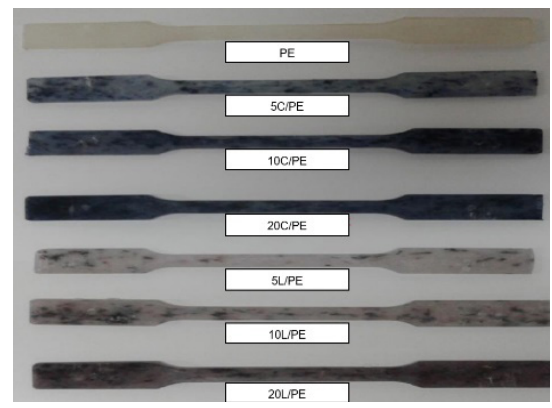

f)

Figure 1. Waste fabric filler material and produced samples. a) waste fabric manually reduced in size, b) waste fabric shredded by the chopper, c) polyethylene pellets used to produce the composites, d) injection molding machine and e) mold used for production, and f) injection molded composite samples.

the specimens were processed in a milling machine (Hammer KF 360A) with the milling depth of $1 \mathrm{~mm}$ at speeds of $171,322,625$ and $1070 \mathrm{rev} / \mathrm{min}$. For each parameter set the longest chips were measured and length values of the 3 longest chips were averaged.

Surface roughness of the samples after the milling procedure were determined using a profilometer (Mitutoyo, Japan). Optical imaging of the specimen surfaces was conducted under a digital microscope (Tagarno, Denmark).

\section{Results and Discussions}

\section{I. Mechanical Testing}

Tensile tests were conducted to investigate the effects of filler type and content on yield, ultimate tensile and fracture strengths of the produced specimens. The tests also gave insight about the effects of different filler type and amounts on the percent elongation values of the specimens at yield and fracture as well as their ultimate percent elongation.
It is visible from the mechanical test results that filler type as well as filler content affect the strength and percent elongation values of the produced composite specimens. In case of linen addition, the yield strength of the samples slightly increases up to $10 \%$ filler content, being more than $2 \%$ higher than that of pure PE, and it drops after further increasing the linen content (Figure 2.a). Cotton addition on the other hand, decreases the yield strength of the samples with increasing cotton content. As compared to cotton, linen results in higher yield strengths for the same amount of filler material.

A similar trend was observed for the ultimate tensile strengths of the samples. Linen addition up to $10 \%$ has a positive effect on the ultimate tensile strength while further addition decreases the ultimate tensile strength (Figure 2.b). Increasing cotton content decreases ultimate tensile strengths of the samples. For filler content of 5 and $10 \%$ linen reinforcement results in higher ultimate tensile strengths compared to cotton reinforcement.

Evaluation of the fracture strengths of the samples show 


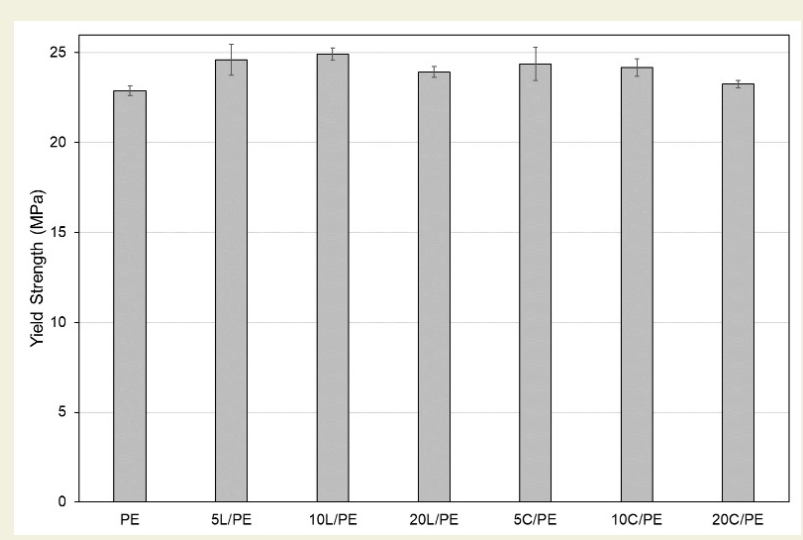

a)

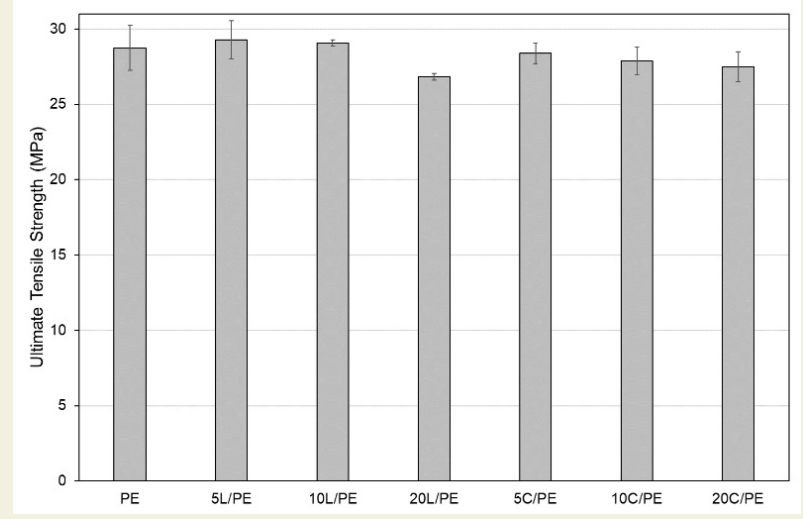

b)

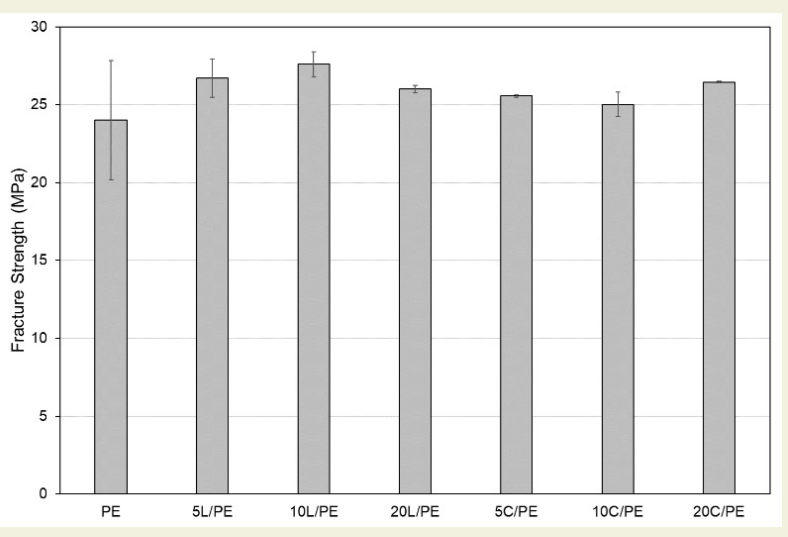

c)

Figure 2. Strengths of the composite specimens with respect to filler type and content a) yield strength, b) ultimate tensile strength, and c) fracture strength.

that linen addition results in an increase more than $10 \%$ in fracture strength while the improvement reaches almost $15 \%$ for $10 \mathrm{~L} / \mathrm{PE}$ sample (Figure $2 . \mathrm{c}$ ). Cotton addition results in an increase of 5 to $10 \%$ in fracture strength depending on the filler content. Comparing effects of filler materials, it was observed that linen addition up to 10 $\%$ results in higher fracture strength values than cotton addition. Regardless of the type and content of filler material all the produced samples have considerably higher fracture strengths (Figure 2.c).

The difference between linen and cotton added samples may be attributed to different mechanical strengths of lin- en and cotton. Obviously, linen having a higher mechanical strength than cotton, it has a more pronounced effect on the mechanical strengths of the samples. However, with increasing amounts of both reinforcements mechanical strength tends to decrease which may be the result of the inhomogeneous nature of the prepared composites. This is also as evidenced by optical microscopy images. Due to the imperfect mixing during the production reinforcement fibers tend to coalesce which result in a decrease of mechanical strengths at higher fiber contents. In addition to this, the difference in the interaction of the filler fibers with the matrix polymer also affects the tensile strengths of the samples. Calegari et al. [21] stated that tensile strength of the samples changed with the matrix polymer material where the same filler materials cause different effects on the tensile strength values in the same polymer matrix.

Considering the percent elongation values (Figure 3) addition of filler material decreases the yield and ultimate elongation characteristics of the samples for both filler material types and with increasing filler amount the percent elongation decreases, as seen in Figure 3.a and 3.b. Linen addition has a very slight effect on the yield elongation up to $10 \%$ (Figure 3.a). On the other hand, cotton addition has been found to increase the elongation up to $10 \%$ while further addition decreases the elongation value below that of pure PE.

For ultimate elongation both filler materials result in a decrease in percent elongation at all contents only the value of $5 \mathrm{C} / \mathrm{PE}$ sample being close to that of pure PE (Figure 3.b).

Important to note is the positive effect of cotton content at small amounts on the fracture elongation values of the sample. $5 \%$ cotton addition results in an increase of almost $30 \%$ of the fracture elongation while $10 \%$ cotton addition still gives positive results (Figure 3.c). The decreasing trend in fracture elongation with increasing content can be observed also for cotton filler as seen in Fig 3.c. However, fracture elongation is adversely affected for in case of linen addition and with increasing filler content the percent elongation values continue to decrease.

Difference in the elongation behaviour of the samples depending on the reinforcement type is thought to be based on different wettability characteristics of linen and cotton fibers with the matrix polymer as a result of which linen reinforced samples tend to show a more brittle behaviour.

\subsection{Hardness Measurements}

Hardness measurements show that hardness values of the produced composites increase with the filler content regardless of the filler material. Although there was some decrease in hardness value for the samples having $5 \%$ linen when compared to the pure PE sample, hardness increased with the increasing linen content and samples 


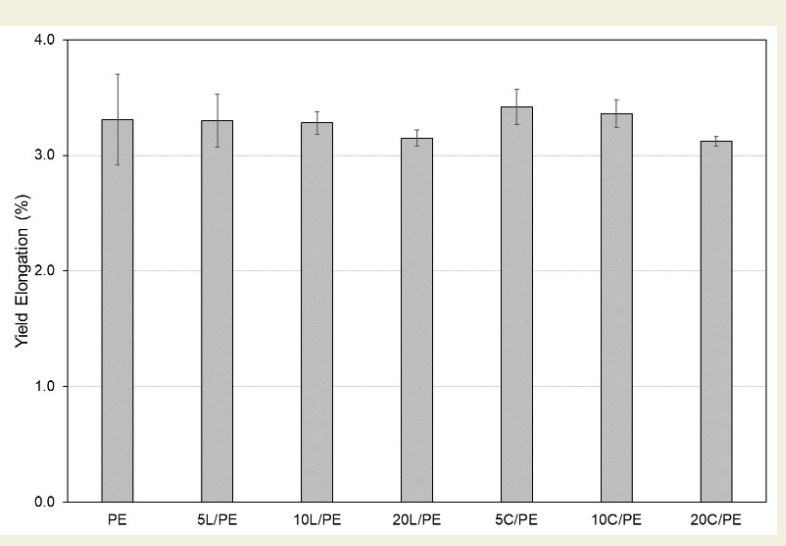

a)

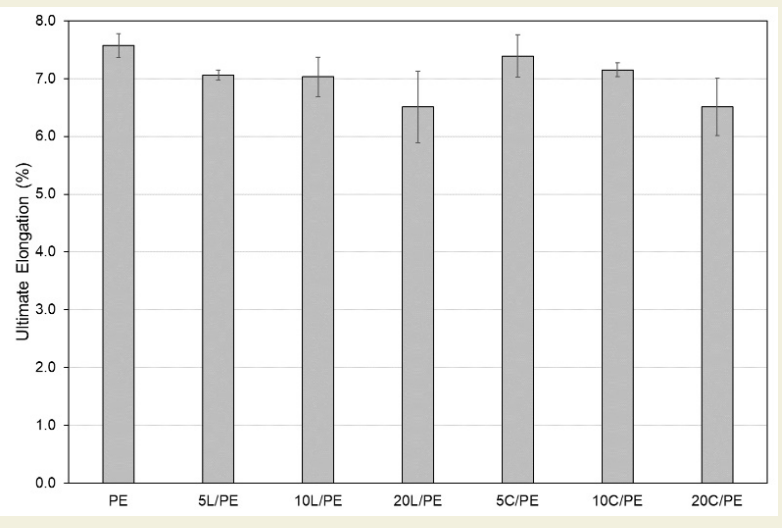

b)

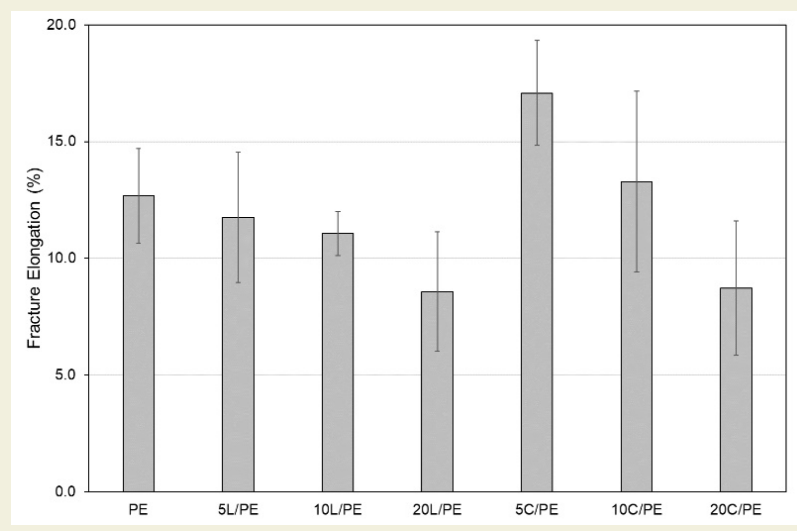

c)

Figure 3. Percent elongations of the composite specimens with respect to filler type and content a) percent elongations at yield, b) ultimate percent elongations, and c) percent elongations at fracture.

containing $20 \%$ linen presented higher hardness value than pure PE (Figure 4). Moreover, regardless of the contents, cotton addition improves the hardness of the specimens such that a $10 \%$ increase in hardness can be achieved with $20 \%$ cotton addition. Independent of the filler type hardness values tend to increase from 5 to 20 $\%$ filler content. This may be due to the polymer matrix impregnating and solidifying in the reinforcement fibers.

\subsection{Surface Roughness and Average Chip Length}

Average surface roughness (Ra) of the samples were observed to depend strongly on the machining speed. As seen in Figure 5, with increasing machining speed average surface roughness of the samples decreased independent of the linen and cotton content. Linen containing samples were observed to have better surface roughness characteristics than cotton containing samples in general. Important to note is that at lower speeds the increase in the surface roughness of linen containing samples were smaller as compared to their cotton containing counterparts.

Measured lengths of the chips obtained at 4 different machining speeds were presented in Figure 6. Average chip length was observed to be almost independent of the waste fiber type and composition but merely dominated by the machining speed. As seen in Figure 6, regardless of the filler materials, average chip lengths were maximum at the machining speed of $322 \mathrm{rpm} / \mathrm{min}$, and there was a decrease in chip length with the increasing speed afterwards.

\subsection{Visual Characteristics}

In order to determine the distribution of the cotton and linen fillers in the produced composite samples, the specimens obtained at each set were examined by using an optical microscope at same magnification (Figure 7). Optical microscopy investigation of prepared samples revealed that a homogenous mixing of waste fibers with the base polymer was obtained both for linen and cotton for all the concentrations. Linen fibers were found to have a more linear alignment as compared to the cotton fibers. Since no additional surface treatment was utilized for the filler additives this observation may be based on the higher surface wettability of linen in polyethylene as compared to cotton. Utilization of waste fiber with a single or varying colors as additives in polyethylene may have a visual appeal by coloring the polymer.

\section{Conclusions}

This study investigates effects of shredded cotton and linen fabric wastes addition on the mechanical properties of commercial polyethylene matrix composites. Use of these textile waste fabrics in polyethylene matrix has a positive impact on the environment by decreasing the polymer consumption and the amount of fabric wastes at same time. Results show that;

- Linen addition has a positive effect on the strength of the produced composites. In particular, addition up to $10 \%$ increases the yield, ultimate and fracture strengths of the produced composites. Addition of cotton waste fabrics have a negative effect on yield and ultimate tensile strengths of the samples while it results in a limited improvement in the fracture strength as compared to control samples.

- Cotton addition in small amounts has a positive effect on the elongation of the samples especially at $5 \%$, while linen addition results in a decrease of the elongation values. 


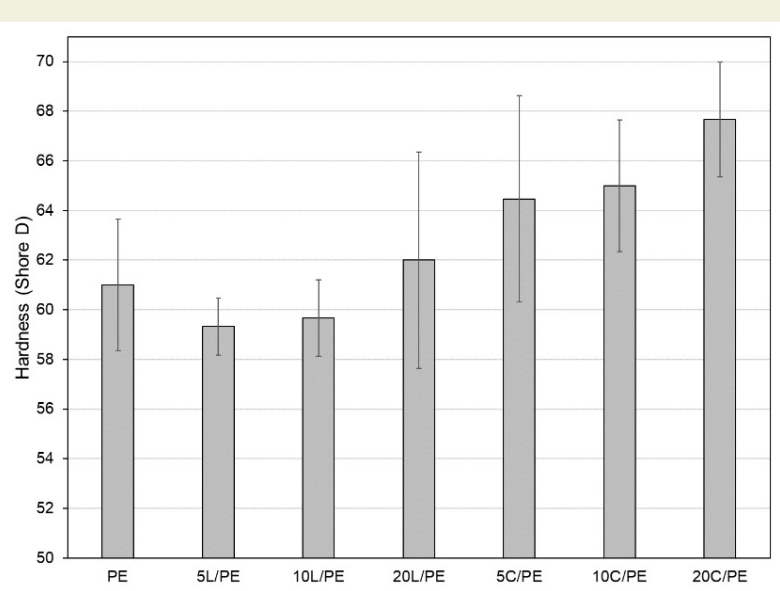

Figure 4. Results of the hardness (Shore D) measurements with respect to filler type and content.

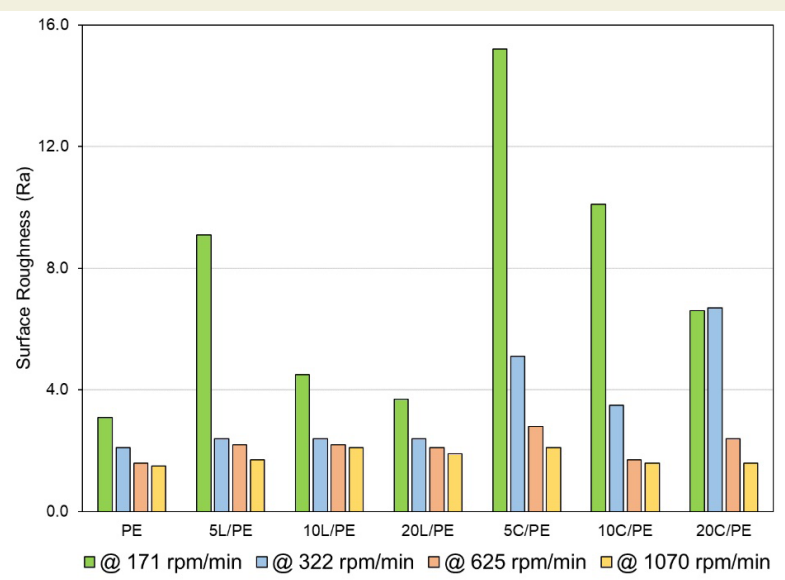

Figure 5. Average surface roughness ( $R a$ ) with respect to filler type and content at various machining speeds.

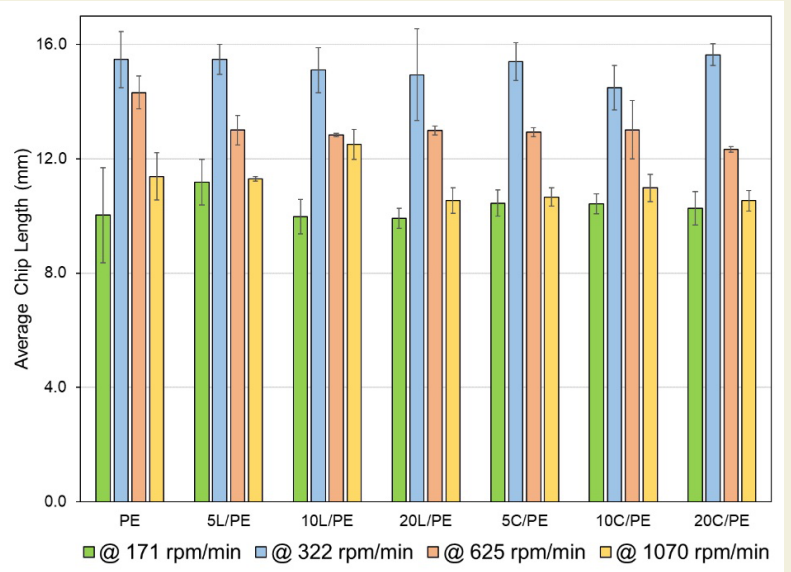

Figure 6. Average chip length with respect to filler type and content at various machining speeds.

- Hardness of the composites can be increased with cotton addition while the effect of linen remains limited.

- Linen addition can be used to improve the strength of PE based composites while cotton addition can be used to enhance the elongation characteristics of the samples.

- Higher machining speeds can be utilized to obtain smooth composite surfaces as evidenced by the decreasing surface roughness with increasing machin-

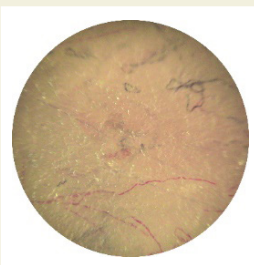

a)

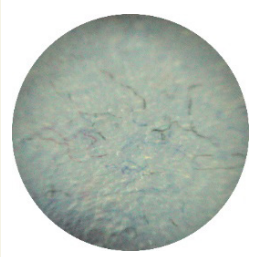

d)

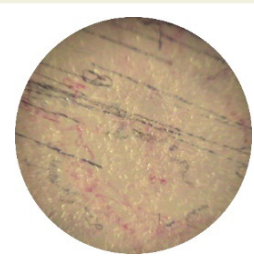

b)

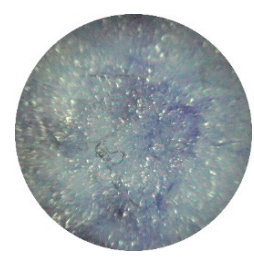

e)

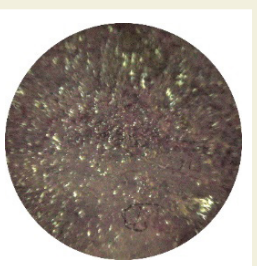

c)

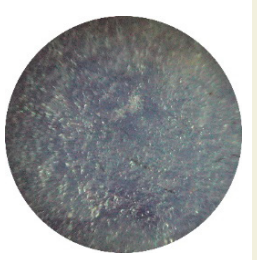

f)
Figure 7. Optical microscopy images of the samples with varying filler type and composition (165x) a) 5L/PE, b) 10L/PE, c) 20L/PE, d) $5 \mathrm{C} / \mathrm{PE}$, e) $10 \mathrm{C} / \mathrm{PE}$, and f) $20 \mathrm{C} / \mathrm{PE}$.

ing speed.

- Addition of linen and cotton waste fabrics into PE improves the visual appeal of the produced composites by imparting the possibility of applying varying color effects depending on the color of the waste fabrics used.

\section{References}

[1] Eser, B., Çelik, P., Çay, A., Akgümüş, D. (2016). Tekstil ve konfeksiyon sektöründe sürdürülebilirlik ve geri dönüşüm olanakları. Tekstil ve Mühendis 23(101): 43-60.

[2] Türkmen Dönmez, E., Türker, E. (2017). Tekstil atıkları içeren yüzeylerin sahip olduğu elektromanyetik kalkanlama, ses ve Isı izolasyonu özellikleriyle ilgili literatür incelemesi. Tekstil ve Mühendis 24(106): 124-135.

[3] Bulut, Y., Erdogan, H. U. (2011). Selüloz esaslı doğal liflerin kompozit üretiminde takviye materyali olarak kullanımı. Tekstil ve Mühendis 18(82), 26-35.

[4] Sha, Z., Wang, F., Zhang, S. F. (2013). Drilling simulation of carbon fiber reinforced plastic composites based on finite element method. Advanced Materials Research 690-693: 2519-2522.

[5] Ferreira, J., Costa, J., Richardson, M. (1997). Effect of notch conditions on the fatigue of a glass-fibre-reinforced polypropylene composite. Composites Science and Technology 57(9-10): 1243-1248.

[6] Tang, W., Santare, M. H., Advani, S. G. (2003). Melt processing and mechanical property characterization of multi-walled carbon nanotube high density polyethylene (MWNT/HDPE) composite films. Carbon 41(14): 27792785.

[7] Kılıçkap, E., Çelik, H. Y. (2012). Cam elyaf takviyeli plastik kompozitlerin frezelenmesinde kesme parametrelerinin yüzey pürüzlülüğüne etkisinin incelenmesi. 3. Ulusal Talaşlı İmalat Sempozyumu (Ankara), 99-103.

[8] Sreenivasulu, R. (2013). Optimization of surface roughness and delamination damage of GFRP composite material in end milling using Taguchi design method and artificial 
neural network. Procedia Engineering 64: 785-794.

[9] Beg, M. D. H., Pickering, K. L. (2008). Mechanical performance of kraft fibre reinforced polypropylene composites: influence of fibre length, fibre beating and hygrothermal ageing. Composites Part A: Applied Science and Manufacturing 39(11): 1748-1755.

[10] Bourmaud, A., Baley, C. (2007). Investigations on the recycling of hemp and sisal fibre reinforced polypropylene composites. Polymer Degradation and Stability 92(6): 1034-1045.

[11] Kim, S. J., Moon, J. B., Kim, G. H., Ha, C. S. (2008). Mechanical properties of polypropylene/natural fiber composites: comparison of wood fiber and cotton fiber. Polymer Testing 27(7): 801-806.

[12] Migneault, S., Koubaa, A., Erchiqui, F., Chaala, A., Englund, K., Krause, C., Wolcott, M. (2008). Effect of fiber length on processing and properties of extruded wood-fiber/HDPE composite. Journal of Applied Polymer Science 110(2): 1085-1092.

[13] Gerikalmaz, S., Bakkal, M., Yılmaz, Ş., Berkalp, B. Ö. (2012). Atık pamuk takviyeli polietilen kompozitlerin sonlu elemanlar modellemesi. Tekstil ve Konfeksiyon 4: 293-300.

[14] Mahdi, E., Dean, A. (2020). The effect of filler Content on the tensile behavior of polypropylene/cotton fiber and poly(vinylchloride)/cotton fiber composites. Materials 13(3): 753-770.

[15] Cavalcanti, D. K. K., Banea, M. D., Neto, J. S. S., Lima, R. A. A., da Silva, L. F. M., Carbas, R. J. C. (2019). Mechanical characterization of intralaminar natural fibre-reinforced hybrid composites. Composites Part B: Engineering 175: 107149.

[16] Aral, N., Berkalp, Ö. B., Bakkal, M., Gök Sadıkoğlu Ü. T. (2009). Atık kumaş takviyeli polimer matrisli kompozitlerin darbe ve çekme davranışlarının incelenmesi. Tekstil ve Konfeksiyon 2: 139-144.

[17] Geng, Y., Li, K., Simonsen, J. (2004). Effects of a compatibilizer system on the flexural properties of wood-polyethylene composites. Journal of Applied Polymer Science 91(6): 3667-3672.

[18] Bateman, S. A., Wu, D. Y. (2000). Composite materials prepared from waste textile fiber. Journal of Applied Polymer Science 81(13): 3178-3185.

[19] Savaş, M., Bakkal, M. (2012). Cam elyafla güçlendirilmiş doğal elyaf takviyeli kompozitlerin geliştirilmesi. 3. Ulusal Tasarım İmalat ve Analiz Kongresi (Ankara) 379-391.

[20] Paiva Junior, C. Z., de Carvalho, L. H., Fonseca, V. M., Monteiro, S. N., d'Almeida, J. R. M. (2004). Analysis of the tensile strength of polyester/hybrid ramie-cotton fabric composites. Polymer Testing 23(2): 131-135.

[21] Calegari, E. P., Porto, J. S., Angrizani, C. C., de Oliveira, B. F., da Cunha Duarte, L., Amico, S. C. (2017). Reuse of waste paper and rice hulls as filler in polymeric matrix composites. Revista Materia 22(2): e-11846.

[22] ISO 527-1:2019 Plastics - Determination of tensile properties. 